Thorax, 1980, 35, 37-41

\title{
Prevention of pneumothorax in needle lung biopsy by breathing $100 \%$ oxygen
}

\author{
Y CORMIER, M LAVIOLETTE, AND A TARDIF \\ From the Centre de Pneumologie de Laval and Département de Radiologie, Hôpital Laval, \\ Quebec, Canada
}

ABSTRACT In an attempt to decrease pneumothorax after transthoracic needle lung biopsy we evaluated the effect of breathing $100 \%$ oxygen during the procedure. Fifty consecutive biopsies on 46 hospital patients were performed on subjects breathing either oxygen or compressed air. The selected gas, chosen randomly, was given for five minutes before the biopsy and continued for 30 minutes after. Twenty-six procedures were on air (group 1) and 24 on pure oxygen (group 2). Four subjects in group 2 were eliminated from analysis because they were unable to sustain the required oxygen breathing. Results showed fewer pneumothoraces with subjects breathing oxygen (four out of 20) than with those breathing air (11 out of 26). Three patients in group 1 required chest tube drainage for symptoms of dyspnoea, but none were required in group 2 . The peak area of gas accumulation for each pneumothorax was smaller in group 2, with a mean surface area of $27 \cdot 1 \mathrm{~cm}^{2}$ (range 9.6-63.8), than in group 1 mean of $68 \cdot 1 \mathrm{~cm}^{2}$ (range 6.4-172.4). The rather surprising finding of fewer pneumothoraces in the oxygen group may be explained by rapid absorption of small leaks immediately after lung puncture. These results were statistically significant $(\mathrm{p}<0 \cdot 05)$. We conclude that $100 \%$ oxygen breathing during transthoracic needle biopsy decreases the number and size of pneumothoraces and propose this simple technique to decrease the morbidity of transthoracic needle lung biopsy.

Transthoracic needle aspiration biopsy is a wellaccepted diagnostic procedure for localised lung disease. However, an incidence of $20-30 \%$ pneumothorax after transthoracic needle biopsy has been reported, ${ }^{1-3}$ and chest tube drainage is often required.

This study was designed to evaluate the effects of denitrogenation with $100 \%$ oxygen during transthoracic needle biopsies. Since most pneumothoraces occur immediately or shortly after the procedure, if the subject inhaled oxygen before, during, and after the biopsy, any resulting pneumothorax would be oxygen filled. As the absorption rate of oxygen in a closed collapsible body cavity far exceeds that of nitrogen, 4 it seemed reasonable to assume that resorption would be enhanced and the need for chest tube drainage decreased.

Address for reprint requests: Dr Y Cormier, Centre de Pneumologie de Laval, Hôpital Laval, 2725 Chemin Ste-Foy, G1V 4G5 Quebec, Canada.

\section{Methods}

Fifty consecutive transthoracic needle lung biopsies in 46 hospital patients were randomly allocated to one of two groups. Subjects were instructed to breathe either $100 \%$ oxygen or compressed air through a mouthpiece. To assure mouth breathing, nose clips were tightly fitted. To document that subjects were breathing $100 \%$ oxygen, mixedexpired oxygen concentration was measured by a Perkin-Elmer MGA1100 mass spectrometer. Neither the patient nor the radiologist doing the procedure knew which gas was inhaled. Both gases were humidified by bubbling through sterile water at room temperature. An adequate reservoir of gas was maintained in a 30-litre rubber bag. Compressed air or oxygen breathing was started five minutes before and continued for 30 minutes after the procedure. All needle biopsies were performed by the same experienced radiologist according to the method of Dahlgren and Nordenstrom, ${ }^{5}$ except that monoplane fluoroscopy was used (Siemen's 
Siregraph). The outer diameter of needle used was $1.2 \mathrm{~mm}$. Usually a single puncture was done at the same biopsy appointment and only rarely were two punctures performed. All biopsies were done in the afternoon between 1400 and 1600 .

Sequential postero-anterior (PA) chest radiographs were obtained before and then 10 minutes, 30 minutes, 90 minutes, and 4.5 hours after the biopsy and at 0800 and 1500 on the next day. If pneumothorax persisted, daily chest radiographs were obtained until total absorption. Only patients with clinically significant dyspnoea were treated by chest tube drainage. Semiquantitative analysis of the pneumothorax was made by measuring the surface area in $\mathrm{cm}^{2}$ of air in the pleural cavity on PA films as described by Northfield. ${ }^{6}$

\section{Results}

Fifty biopsies, 26 breathing air and 24 oxygen were performed on 46 patients. Two patients underwent one biopsy with air and one with oxygen. One patient had two biopsies with air and one had two biopsies with oxygen. Results include data from 26 biopsies on air (group 1) and 20 on $100 \%$ oxygen (group 2). Four subjects in group 2 were eliminated from analysis because they were unable to sustain oxygen breathing for the required period. In group 2 mean value of expired oxygen fraction measured within five minutes after biopsy procedure was 0.9 with a range from 0.70 to 0.96 . Tables 1 and 2 contain data on patients characteristics and biopsy procedures for each group.

Eleven subjects in group $1(42 \%)$ and four in group $2(20 \%)$ had a pneumothorax after the biopsy procedure. Pneumothorax areas measured on PA films are presented in table 3. For group 2, two pneumothoraces were small and did not increase after oxygen withdrawal-one had disappeared and one was barely visible on the follow-

Table 1 Comparative patient data

\begin{tabular}{llllll}
\hline & \multicolumn{2}{c}{ Group 1 (air) } & & \multicolumn{2}{c}{ Group 2 } \\
\cline { 2 - 3 } \cline { 5 - 6 } \cline { 5 - 6 } & Total & $\begin{array}{c}\text { With } \\
\text { pneumothorax }\end{array}$ & & Total & $\begin{array}{l}\text { With } \\
\text { pneumothorax }\end{array}$ \\
\hline Number* & 26 & 11 & & 20 & 4 \\
Sex (F/M) & $8 / 18$ & $2 / 9$ & & $5 / 15$ & $2 / 2$ \\
Age (yr) & $23-74$ & $24-70$ & & $41-82$ & $57-82$ \\
Mean & $58 \cdot 2$ & 60 & & 62 & 66 \\
Smoking & 17 & 5 & & 15 & 3 \\
$(>15$ cig/day) & & & & &
\end{tabular}

*All patients who had two biopsies are recorded twice. Two underwent one biopsy on air breathing and one on oxygen. Of these, one had pneumothorax with both techniques, the other had none. One patient had two biopsies on air and one had two biopsies on oxygen. There was no pneumothorax in either patient.
Table 2 Comparative data on biopsy procedures

\begin{tabular}{|c|c|c|c|c|c|}
\hline & \multicolumn{3}{|c|}{ Group 1 (air) } & \multicolumn{2}{|c|}{ Group $2(100 \%$ oxygen $)$} \\
\hline & Total & & $\begin{array}{l}\text { With } \\
\text { pneumothorax }\end{array}$ & Total & $\begin{array}{l}\text { With } \\
\text { pneumothorax }\end{array}$ \\
\hline Number & 26 & 11 & & 20 & 4 \\
\hline $\begin{array}{l}\text { Pleural } \\
\text { thickening }\end{array}$ & 6 & 1 & & 3 & 0 \\
\hline $\begin{array}{l}\text { Diagnosis } \\
\text { by biopsy }\end{array}$ & 15 & 6 & & 12 & 1 \\
\hline $\begin{array}{l}\text { Final diagnosi } \\
\text { Cancer } \\
\text { Tuberculosi } \\
\text { Others* }\end{array}$ & $\begin{array}{l}\text { sis } \\
14 \\
\text { sis } 3 \\
9\end{array}$ & $\begin{array}{l}6 \\
2 \\
3\end{array}$ & & $\begin{array}{r}10 \\
4 \\
6\end{array}$ & $\begin{array}{l}2 \\
0 \\
2\end{array}$ \\
\hline $\begin{array}{c}\text { Depth of lesio } \\
0.0 \dagger- \\
1.9 \mathrm{~cm} \\
2.0- \\
4.9 \mathrm{~cm} \\
>5.0 \mathrm{~cm}\end{array}$ & $\begin{array}{r}\text { on } \\
11 \\
9 \\
6\end{array}$ & $\begin{array}{l}2 \\
4 \\
5\end{array}$ & & $\begin{array}{l}7 \\
6 \\
7\end{array}$ & $\begin{array}{l}0 \\
1 \\
3\end{array}$ \\
\hline
\end{tabular}

*Interstitial pneumonitis (four), metastasis (two), aspergillosis (one), blastomycosis (one), Wegener's granulomatosis (three), bronchiectasis (one), unknown (three).

†Contiguous with pleura.

ing day. The other two had a small surface areao at 10 and 30 minutes, one enlarged at 1.5 hour, the other at 4.5 hours then stabilised. None re-o quired chest tube drainage.

In group 1 , nine of the 11 pneumothoraces were greater than those in group 2; of these, three re-ō quired chest tube drainage. In six subjects pneu- 3 mothorax appeared later than 30 minutes after the biopsy (table 3).

Mean surface area, obtained by dividing the total pneumothorax areas for each group by the number of biopsy procedures, is presented in fig $1 \times$ Both groups peaked at 4.5 hours after the biopsy The apparent large drop in the quantity of pneut mothorax between 4.5 and 0800 hours for group $f$ does not represent actual absorption, but results from chest tube drainage in two subjects.

Figure 2 demonstrates the similarity in absorp? tion rate for each group. To arrive at a mearr. effective absorption rate only subjects for whoms we have available data at each time interval up to 15 hours (on second day) are included. Seven subన jects from group 1 and four from group 2 qualifie $\alpha_{0}^{j}$ for this analysis.

\section{Discussion}

With pure oxygen breathing, pneumothoraces oc훙 curred less frequently, were smaller, and did noळ increase after 4.5 hours post biopsy. Statistica? analysis was hindered by the need for chest tube drainage which eliminated three subjects with large pneumothorax from group 1. In order to 
Table 3 Pneumothorax surface areas $\left(\mathrm{cm}^{2}\right)$ in subjects from both groups

\begin{tabular}{|c|c|c|c|c|c|c|}
\hline \multirow[t]{3}{*}{ Cases } & \multicolumn{6}{|c|}{ Time after biopsy } \\
\hline & \multicolumn{4}{|c|}{ First day } & \multicolumn{2}{|c|}{ Second day } \\
\hline & $10 \min$ & $30 \mathrm{~min}$ & $1 \cdot 5 h$ & $4 \cdot 5 h$ & 0800 & 1500 \\
\hline \multicolumn{7}{|c|}{ Group 1 (air) } \\
\hline 1 & $76 \cdot 6$ & $63 \cdot 8 *$ & - & - & - & - \\
\hline 5 & $9 \cdot 6$ & $25 \cdot 5$ & $60 \cdot 7$ & $60 \cdot 7$ & $57 \cdot 6$ & $47 \cdot 9$ \\
\hline 6 & 0.0 & 0.0 & $166 \cdot 0$ & $172 \cdot 4^{*}$ & - & - \\
\hline 9 & $0 \cdot 0$ & 0.0 & 6.4 & $6 \cdot 4$ & $6 \cdot 4$ & $6 \cdot 4$ \\
\hline 14 & 0.0 & 0.0 & $47 \cdot 9$ & $57 \cdot 5^{*}$ & - & - \\
\hline 15 & 0.0 & 0.0 & $6 \cdot 4$ & $38 \cdot 3$ & $47 \cdot 7$ & $38 \cdot 3$ \\
\hline 17 & $9 \cdot 6$ & $19 \cdot 1$ & $63 \cdot 8$ & $73 \cdot 4$ & $89 \cdot 4$ & $83 \cdot 0$ \\
\hline 31 & 0.0 & 0.0 & $35 \cdot 1$ & $41 \cdot 5$ & $41 \cdot 5$ & $25 \cdot 6$ \\
\hline 33 & 0.0 & $0 \cdot 0$ & 0.0 & $51 \cdot 1$ & $102 \cdot 2$ & $-\dagger$ \\
\hline 35 & $33 \cdot 5$ & $67 \cdot 0$ & $67 \cdot 0$ & $70 \cdot 2$ & $57 \cdot 5$ & $47 \cdot 9$ \\
\hline 44 & $24 \cdot 6$ & $9 \cdot 6$ & $16 \cdot 0$ & $16 \cdot 0$ & $12 \cdot 8$ & $6 \cdot 4$ \\
\hline Total & 153.9 & $185 \cdot 0$ & $588 \cdot 0$ & $587 \cdot 5$ & $415 \cdot 0$ & - \\
\hline \multicolumn{7}{|c|}{ Group 2 (oxygen $100 \%$ ) } \\
\hline 16 & $6 \cdot 4$ & $6 \cdot 4$ & $16 \cdot 0$ & $9 \cdot 6$ & $6 \cdot 4$ & $6 \cdot 4$ \\
\hline 20 & $9 \cdot 6$ & $9 \cdot 6$ & $3 \cdot 2$ & $6 \cdot 4$ & $3 \cdot 2$ & very small + \\
\hline 28 & $19 \cdot 1$ & $19 \cdot 1$ & $0 \cdot 0$ & $0 \cdot 0$ & $0 \cdot 0$ & 0.0 \\
\hline 43 & $12 \cdot 8$ & $6 \cdot 4$ & $16 \cdot 0$ & $63 \cdot 8$ & $51 \cdot 1$ & $51 \cdot 1$ \\
\hline Total & $47 \cdot 9$ & $41 \cdot 5$ & $35 \cdot 2$ & $79 \cdot 8$ & $60 \cdot 7$ & $57 \cdot 5$ \\
\hline
\end{tabular}

*Last value before chest tube drainage.

†Not available.

¥ Considered as zero for computation.

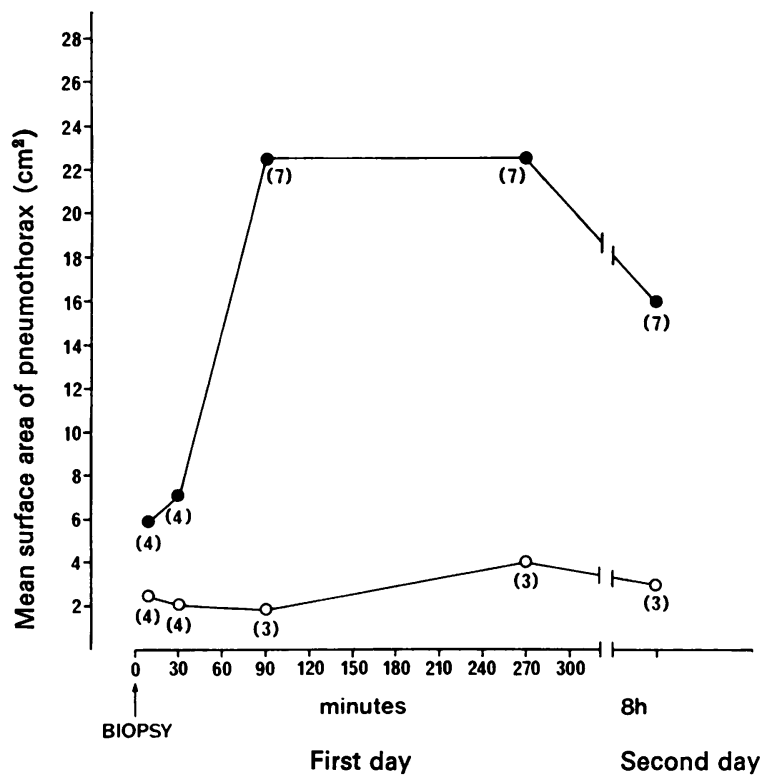

minimise this artefact, we assumed that the surface area for case 1 would have remained at least equal to its pre-drainage value for up to 4.5 hours after biopsy. This seems justified since no pneumothorax in group 1 decreased before 4.5 hours. We believe this pneumothorax actually increased before drainage. On returning to the ward, the patient became progressively more dyspnoeic, and a chest tube was inserted before a control radio-
Fig 1 Mean surface area of pneumothorax in both groups: $=$ group 1 (a:r), $\bigcirc=$ group 2 $(100 \%$ oxygen $)$. Numbers in parentheses indicate number of pneumothoraces at each interval. graph could be obtained. For analysis the last measured value of $63.8 \mathrm{~cm}^{2}$ was, therefore, added to the 1.5 and 4.5 hours results. With this correction pneumothorax differences between group 1 and 2 were statistically significant at 4.5 hours after biopsy (U test of Mann-Whitney, $\mathrm{p}<0.05$ ).

Since the objective of our study was to decrease the size of any pneumothorax, we compared results of peak pneumothorax area for each subject in 


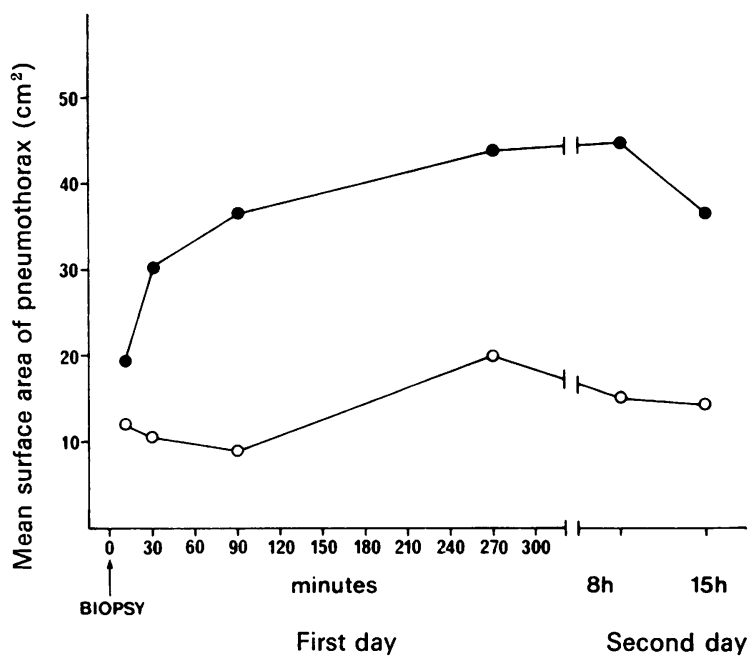

Fig 2 Mean effective absorption rate for pneumothorax in each group: $=$ group 1 (air), $\mathrm{O}=$ group $2(100 \%$ oxygen). Data from seven patients in group 1 and four in group 2.

both groups, regardless of time. This gave a mean surface area of $27 \cdot 1 \mathrm{~cm}^{2}$ (range $9 \cdot 6-63 \cdot 8$ ) in group 2 and $68.1 \mathrm{~cm}^{2}$ (range $6.4-172.4$ ) in group 1 . This was significant by the standard $t$ test $(\mathrm{p}<0.05)$. Since our results are not symmetrically distributed, the value of a $t$ test may be criticised. We, therefore, also compared these values with the $U$ test which gave a $p$ value of 0.578 . This value may be underestimated since the three subjects in group 1 who required chest tubes probably had greater pneumothorax at drainage than our peak measurement. The absorption rate was however similar for both groups.

These results were somewhat surprising. We did not expect fewer pneumothoraces with oxygen, but faster absorption. We could not explain our data on group differences. Both groups were similar in all aspects evaluated and the biopsy procedures were not different for the two groups (cf tables 1 and 2). The radiologist doing the procedure did not know if the subjects were breathing oxygen or air. Although our data were not what we initially expected we believe they can be explained by the variable evaluated, that is oxygen versus air breathing.

Previous studies on gas absorption rates have demonstrated clearly that an oxygen filled closed collapsible cavity absorbs faster than an ambient air filled cavity. ${ }^{4}$ This is related to higher pressure gradient between cavity and venous blood, and higher solubility and diffusion coefficient of oxygen than nitrogen. Studies by Dale and Rahn ${ }^{7}$ showed that the absorption rate of an oxygen filled lung is 62 times faster than for a nitrogen filled one. The actual quantitative absorption of gases in the pleural space, because of pleural area and thick-

ness, would theoretically be less than for a whole $\overrightarrow{0}$ lung; however the ratio for oxygen : nitrogen ab-o sorption should be similar. Therefore one cano expect a much faster initial resorption with oxy gen filled pneumothorax than air filled one. If the subject breathes oxygen until the absorption iso completed the rate always remains faster than ford an air filled cavity. On the other hand, when the subject is returned to air, a new equilibration of gases' partial pressures in the cavity occurs. On? returning to air breathing, the gas fractions in the cavity attain a constant composition, no matter which gas was originally introduced. This state of constant composition in an oxygen filled cavity, should be obtained when $60 \%$ of its volume has been absorbed. ${ }^{4}$ During this equilibrating perio $B$. the absorption rate in group 2 should be greate than group 1 , but become similar when the steady state is obtained.

In group 2, while the subject is maintained on? oxygen, any leak would be rapidly absorbed. It is quite conceivable that for most patients smali oxygen leaks (through the hole of an 18-gauger needle) were absorbed before radiologically visibles gas accumulation could occur. This could allow rapid visceral and parietal pleural adhesion, thus occluding the puncture site. This hypothesis is supported by the fact that none of the subjects in group 2 developed pneumothorax after 10 minutes? On the other hand we may postulate that with air;o such small leaks did not accumulate enough volo ume to be seen on initial roentgenograms but since्? resorption was slow, close contact of the two pleural membranes did not occur and clinically evident pneumothorax eventually appeared.

The similar number of immediate pneumo 
thoraces (within 10 minutes) in both groups further supports our hypothesis. No new pneumothorax developed beyond 10 minutes in group 2, while six appeared in group 1. This is a major difference between the two groups and can be explained by the rapid absorption and occlusion of small leaks on oxygen.

Theoretically, absorption rate in oxygen filled pneumothorax should be faster during the 30 minutes of oxygen breathing and up to the resorption of $60 \%$ of its volume upon returning to air breathing. However this was not seen (fig 2 ). Since leaks continued during the first 4.5 hours, as demonstrated by the actual pneumothorax volume increase during this period, any leak after the initial 30 minutes involved air and thus decreased the oxygen partial pressure in the group 2 pneumothoraces. We believe pneumothoraces that appeared in group 2 represent larger puncture holes and that the leak was partially compensated by the initially enhanced oxygen absorption. This could explain the other major difference between groups 1 and 2-that is, the smaller size of pneumothoraces in group 2.

We conclude that breathing $100 \%$ oxygen for five minutes before and 30 minutes after transthoracic needle lung biopsy may prevent pneumothorax and the need for chest tube drainage. We propose this simple technique to decrease the morbidity of an effective diagnostic procedure. This is specially useful since biopsies are frequently done on an outpatient basis (49.5\%). ${ }^{2}$ Thirty minutes of
$100 \%$ oxygen breathing is not deleterious for the patient ${ }^{8}$ but may be inconvenient for a busy radiologist. Since no pneumothorax appeared 10 minutes after biopsy in group 2 , it is conceivable that 10 minutes of oxygen breathing may be adequate to decrease the morbidity of needle lung biopsy. This would be much less cumbersome for all involved. Further studies are needed to verify this point.

\section{References}

1 Herman PG Hessel SJ. The diagnostic accuracy and complications of closed lung biopsies. Radiology 1976; 125:11-14.

2 Lalli AF, McCormack LJ, Zelch M, Reich NE, Belovich D. Aspiration biopsies of chest lesions. Radiology 1977; 127:35-40.

3 Sinner WN. Complications of percutaneous transthoracic needle aspiration biopsy. Acta Radiol (Diagn) 1976; 17:813-28.

4 Piiper J. Physiological equilibria of gas cavities in the body. In: Fenn NO, Rahn H, eds. Handbook of Physiology, vol 4, Respiration. Washington: American Physiological Society, 1965:1205-18.

5 Dahlgren S, Nordenström B. Transthoracic needle biopsy. Stockholm: Almqvist and Wiksell, 1966.

6 Northfield TC. Oxygen therapy for spontaneous pneumothorax. Br Med J 1971; 4:86-8.

7 Dale WA, Rahn H. Rate of gas absorption during atelectasis. Am J Physiol 1952; 170:606-15.

8 Winter PM, Smith G. The toxicity of oxygen. Anesthesiology 1972; 37:210-41. 